\title{
Vibrational and Thermal Properties of Ionic Conductors Type Pirochlore $\mathrm{H}_{1-\mathrm{x}} \mathrm{Ag}_{\mathrm{x}} \mathrm{TaWO}_{6} \cdot \mathrm{nH}_{2} \mathrm{O}$
}

\author{
Daniel Valim ${ }^{1 *}$, Souza Filho $\mathrm{AG}^{2}$, Filho $\mathrm{JM}^{2}$, Alves $\mathrm{OL}^{3}$, de Santis MAC ${ }^{3}$ and Silva $\mathrm{EN}^{4}$ \\ ${ }^{1}$ Department of Mathematics, UNEMAT/Sinop, Brazil \\ ${ }^{2}$ Department of Physics, UFC/Fortaleza, Brazil \\ ${ }^{3}$ Department of Chemistry, UNICAMP/Campinas, Brazil \\ ${ }^{4}$ Department of Physics, Federal University of Maranhão/São Luíz, Brazil
}

\begin{abstract}
We have studied, by Raman spectroscopy, materials $\mathrm{H}_{1-\mathrm{x}} \mathrm{Ag}_{\mathrm{x}} \mathrm{TaWO}_{6}$ and $\mathrm{KTaWO}_{6}$, both belonging to the pyrochlore system whose symmetry $\mathrm{Fd} 3 \mathrm{~m}\left(\mathrm{O}_{h}{ }^{7}\right)$. The experiments consisted in measurements of the Raman spectrum, at room temperature, on samples, before and after heat treatment. We have not performed photoinduced transformations studies on samples subjected to strong illumination. Instead of, we performed the heat treatment temperature of $700^{\circ} \mathrm{C}$, where the transition phase takes place. Studies using the Group Theory were performed to describe the changes observed in the spectra as a function of heat treatment at different temperatures. During these studies, along with a comparison with information in the literature, it was possible to better understanding the thermal stability of the material. Our studies showing by both Raman spectroscopy and DSC/TG techniques there was not significant loss of mass. It means the samples may have performed transitions to defective pyrochlore phase $\mathrm{AgTaWO}_{6}$.
\end{abstract}

Keywords: Group theory; Spatial group; Empirical equation; Raman spectroscopy; Vibrational modes

\section{Introduction}

The group of pyrochlore is chemically diverse. Hogarth cited by Chelgani [1] defined the formula of pyrochlore oxides as $\mathrm{A}_{2-\mathrm{m}} \mathrm{B}_{2} \mathrm{O}_{6}$ $\phi_{1-\mathrm{n}} \cdot \mathrm{pH}_{2} \mathrm{O}$ where $\mathrm{A}$ represents an element mono-, di-, or trivalent, $\mathrm{B}$ represents an element tri-, tetra-, penta-, or hexavalent and $\phi=\mathrm{O}, \mathrm{OH}$, F. The structures of pyrochlore are classified according to the cation distribution in sites $\mathrm{A}$ and anions in sites $\phi$ as normal, ideal, defective and reverse. For normal pyrochlore there is a regular distribution of atoms on the A sites (at positions 16d, Wyckoff notation) and $\phi$ (at positions 18b). A typical pyrochlore has an intermediate structure between the ideal and defective structures, which are set to $\mathrm{m}=0$ (complete A cation) and $\mathrm{m}=2$ (absent A cation). Some of the normal pyrochlore's related structures show an inverse distribution of A cations and site $\phi$ vacancies, namely the A cations (with $\mathrm{m}<1$ ) occupy positions $8 \mathrm{~b}$ while the vacancies occupy the positions $16 \mathrm{~d}$. The defective pyrochlores belong to a class of cationic materials that have been extensively studied in the past years, such as in the search for good solid ionic conductors for technological applications [2] as for model systems to study ion conduction [3].

The compounds under investigation in this work are of type $m=1$, $\mathrm{n}=1, \mathrm{p}=0,0.5$ or 1 . Many pyrochlores with the general chemical formula $\mathrm{AB}^{\prime} \mathrm{B}^{\prime} \mathrm{O}_{6}$, as the $\mathrm{HTaWO}_{6}[4]$ has random distribution of cations $\mathrm{B}^{\prime}$ and $\mathrm{B}$ " in the center of the octahedrons. These belong to a class of materials, in which 450 synthetic compositions with properties that include: catalysis, piezoelectricity, iron and iron magnetism, luminescence and colossal magnetoresistance $[5,6]$. Other pyrochlores exhibit another collection of interesting physical properties such as semiconducting and superconductivity $[7,8]$

These compounds crystallize in the space group $\mathrm{Fd} 3 \mathrm{~m}\left(\mathrm{O}_{\mathrm{h}}{ }^{7}\right)$, with eight molecules per unit cell $(\mathrm{Z}=8)$. In this structure the atoms $\mathrm{B}$ and $\mathrm{X}$ form a matrix of octahedral $\left(\mathrm{BX}_{6}\right)$ connected by vertices while $\mathrm{Y}$ and $\mathrm{A}$ form another array of tetrahedral $\left(\mathrm{YA}_{4}\right)$ sharing vertices. This structure is analogous to other types of structures such as those of the $\mathrm{ReO}_{3}$ and perovskite $\mathrm{CaTiO}_{3}$. However, in the pyrochlore the unit skeleton $\left(\mathrm{BO}_{6}\right.$ ${ }_{n}$ is more complex and the cavities left by them are more open than in the other two cases. These cavities have an average diameter between 3.8 and $4.6 \AA$ [9].

\section{Experimental Procedure}

\section{Sample synthesis}

The pyrochlore precursor $\mathrm{KTaWO}_{6}$ samples were synthesized via solid-state reactions from stoichiometric amounts of the reactants. The reactants were $\mathrm{K}_{2} \mathrm{CO}_{3}$ (Riedel - 99\%), $\mathrm{Ta}_{2} \mathrm{O}_{5}(\mathrm{Alfa}-99 \%)$ and Tungsten oxide $\mathrm{WO}_{3}$ (Aldrich) with $99 \%$ of purity. The reagents and their both manufacturer and purity are shown in Table 1.

The reactions can be viewed as follows:

$$
\mathrm{K}_{2} \mathrm{CO}_{3}+\mathrm{Ta}_{2} \mathrm{O}_{5}+2 \mathrm{WO}_{3} \rightarrow 2 \mathrm{KTaWO}_{6}+\mathrm{CO}_{2}
$$

The procedure is an adaptation of procedure described by Mari [10]. The reagents were crushed and mixing in an agate mortar for 10 minutes. The system remained under heating for 45 hours, and every 15 hours the reaction was stopped for crushing and homogenization of the mixture.

The pyrochlore $\mathrm{HTaWO}_{6} \cdot \mathrm{H}_{2} \mathrm{O}$ compound was obtained by ionic exchange reaction between $\mathrm{KTaWO}_{6}$ and a 12 mol. $\mathrm{L}^{-1} \mathrm{HCl}$ solution. The system was left under stirring at room temperature for 48 hours, with two exchanges of the supernatant solution after centrifugation of the solid.

The $\mathrm{HTaWO}_{6}$ was submitted at new ionic exchange reaction. The proton ion was exchanged by $\mathrm{Ag}^{+}$to make $\mathrm{AgTaWO}_{6}$. The reactions

*Corresponding author: Daniel Valim, Department of Mathematics, UNEMAT/ Sinop, Brazil, Tel: +55(66)3511-2156; E-mail: daniel.valim@unemat.br

Received June 25, 2018; Accepted September 12, 2018; Published September 22, 2018

Citation: Valim D, Filho AGS, Filho JM, Alves OL, de Santis MAC, et al. (2018) Vibrational and Thermal Properties of lonic Conductors Type Pirochlore $\mathrm{H}_{1}$ ${ }_{x} \mathrm{Ag}_{\mathrm{x}} \mathrm{TaWO}_{6} \cdot \mathrm{nH}_{2} \mathrm{O}$. J Material Sci Eng 7: 483. doi: 10.4172/2169-0022.1000483

Copyright: @ 2018 Valim D, et al. This is an open-access article distributed under the terms of the Creative Commons Attribution License, which permits unrestricted use, distribution, and reproduction in any medium, provided the original author and source are credited. 


\begin{tabular}{|l|c|c|}
\hline Reagent & Formula & Manufacturer \\
\hline Tantalum Dioxide & $\mathrm{Ta}_{2} \mathrm{O}_{5}$ & Alfa \\
\hline Tungsten Oxide & $\mathrm{WO}_{3}$ & Aldrich \\
\hline Potassium Carbonate & $\mathrm{K}_{2} \mathrm{CO}_{3}$ & Riedel \\
\hline Silver Nitrate & $\mathrm{AgNO}_{3}$ & 99 \\
\hline Nitric Acid & $\mathrm{HNO}_{3}$ & Merck \\
\hline Hydrochloric Acid & $\mathrm{HCl}$ & Aldrich \\
\hline${ }^{*}$ Concentration in aqueous solution. & & 99 \\
\hline
\end{tabular}

Table 1: Characteristics of used reagents.

were performed using the procedures of LQES laboratory for similar compounds $[11,12]$. In this part of work, the reactions were optimized for a maximum exchange proton-silver. The compounds were dipping in $\mathrm{AgNO}_{3}$ solution with a concentration of $10^{-3}$ at $10^{-2}$ mol. $\mathrm{L}^{-1}$ and stirring by magnets at room temperature during 48 hours.

Finally, the protonated compounds were again subjected to ion exchange reactions, this time the proton was replaced by $\mathrm{Ag}^{+}$ions. The reactions were performed using the procedures of LQES laboratory for similar compounds $[11,12]$. For this time, the reactions were performed by molar rations of 4:1, 2:1, 1:1, 1:2, 1:4 and 1:8 to form $\mathrm{H}_{1-\mathrm{x}} \mathrm{Ag}_{\mathrm{x}} \mathrm{TaWO}_{6}$. $\mathrm{H}_{2} \mathrm{O}$.

The compounds were immersed in aqueous $\mathrm{AgNO}_{3}$ solutions and magnetically stirred at room temperature for 48 hours. The solids were then separated by centrifugation and washed with deionized water. The washing and purification process was repeated three times.

Our work consisted of a similar study of reference [13], where the $\mathrm{HTaWO}_{6}$ pyrochlore samples were submitted substitutional homovalent doping with silver by an ion exchange reaction, i.e., the proton of the compound was replaced by $\mathrm{Ag}^{+}$to form compounds of type $\mathrm{H}_{1-\mathrm{x}} \mathrm{Ag}_{\mathrm{x}} \mathrm{TaWO}_{6}$ [14]. The reactions were performed using the procedures of LQES laboratory for similar compounds $[11,12]$. The molar ratio $\mathrm{H}: \mathrm{Ag}$ of each of the samples were 4:1, 2:1, 1:1, 1:2 and 1:4, the code samples are HAg1: 0.25, HAg1: 0.5 , HAg1: 1, HAg1:2 and HAg1:4. We know the ion exchange reaction, to 4:1(Hag1:0.25) for example, occurs as follows

$$
4 \mathrm{HTaWO}_{6}+1 \mathrm{AgTaWO}_{6} \rightarrow 5 \mathrm{H}_{0.8} \mathrm{Ag}_{0.2} \mathrm{TaWO}_{6}
$$

Where we can adjust the $\mathrm{x}$, which is the concentration ratio of silver to 0.2 . For the other compounds, with names HAg1:0.5, HAg1:1, HAg1:2 and HAg1:4, $\mathrm{x}$ values are $0.33,0.50,0.67$ and 0.80 , respectively.

\section{$\mathrm{X}$-ray diffraction}

After sample synthesis, the X-ray diffractogram was obtained in a Shimadzu diffractometer, operating in scan mode with $\mathrm{CuKa}$ radiation, generated at $40 \mathrm{KV}$ and $30 \mathrm{~mA}$ current [14]. The scanning speed used was $2 / \mathrm{min}$ in $2 \theta$, with accumulation for reading every 0.6 seconds. The slits used were: divergent $1.0 \mathrm{~mm}$ and collection $0.3 \mathrm{~mm}$. The calibration of the scanning angle was done with polycrystalline silicon and the samples were analyzed in powder form.

In the Figure 1 is shown the $\mathrm{X}$-ray diffraction pattern for all $\mathrm{H}_{1}$. $\mathrm{Ag}_{\mathrm{x}} \mathrm{TaWO}_{6} \cdot \mathrm{nH}_{2} \mathrm{O}$ pyrochlore samples. We can see all peak indicate that structures belong to the $\mathrm{Fd} 3 \mathrm{~m}\left(\mathrm{O}_{\mathrm{h}}{ }^{7}\right)$ space group, in according with reference [10], with eight molecules per unit cell. No significant structural change occurred beyond variations in relative intensities to specific peaks.

\section{FTIR spectroscopy}

The Fourier Transform Infrared (FTIR) spectra were obtained

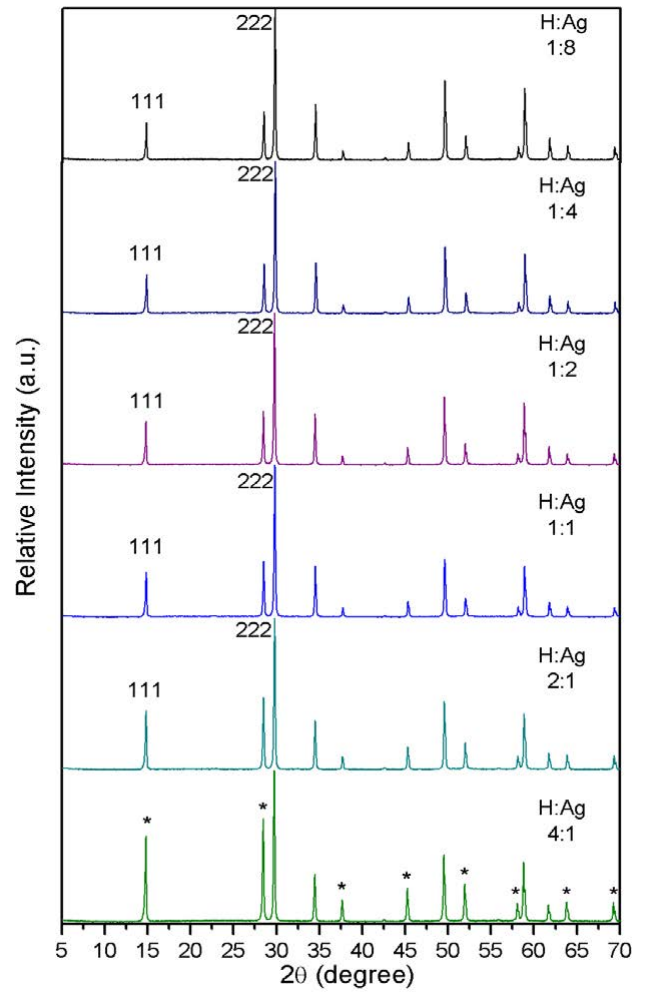

Figure 1: X-ray diffraction patterns for all samples synthesized in the LQES laboratory. The asterisks indicate the peaks where there are significant changes in the intensities [14].

by Bomen ABB-FTLA 2000 in the 250-4000 $\mathrm{cm}^{-1}$ interval with $4 \mathrm{~cm}^{-1}$ resolution and 16 accumulations. The samples were studied in $\mathrm{KBr}$ pellets from Fluorolube dispersion, for spectra in the $1300-4000 \mathrm{~cm}^{-1}$, and in Nujol, for $250-1300 \mathrm{~cm}^{-1}$, using cesium-iodide windows. The FTIR measurements were made in the LQES laboratory [14].

\section{DSC-TG}

We have performed the Differential Scanning Calorimetry and Thermogravimetry(DSC/TG) experiments. The results were obtained in the Crystal Characterization Laboratory of the Physics Department of UFC. The $\mathrm{H}_{1-\mathrm{x}} \mathrm{Ag}_{\mathrm{x}} \mathrm{TaWO}_{6} \cdot \mathrm{H}_{2} \mathrm{O}$ pyrochlore samples studied was $\mathrm{x}=(0.8,0.67,0.50$ and 0.20$)$. The equipment used was Netzsch STA 409 $\mathrm{PC} / \mathrm{PG}$. The temperature range was $25-570^{\circ} \mathrm{C}$ with $10^{\circ} \mathrm{C} / \mathrm{min}$ heating rate. Each sample was crushed and placed in aluminum cadmium with masses around $5 \mathrm{mg}$ on average.

The Sample masses for $\mathrm{x}$ concentration rate $0.80,0.67,0.50$ and 0.20 was $6.34,5.56,6.07$ and $4.67 \mathrm{mg}$, respectively. 


\section{Raman spectroscopy}

All Raman measurements were performed at room temperature using the following experimental apparatus: an argon laser, a triple monochromator spectrometer Jobin Yvon T64000 equipped with a microscope using a $180 \mathrm{~mm}$ focal distance lens. The laser line was of $488 \mathrm{~nm}$ wavelength whose power was $300 \mathrm{~mW}$ on the samples with structure pyrochlore. The experiments were performed on samples $\mathrm{KTaWO}_{6}$ and $\mathrm{H}_{1-\mathrm{x}} \mathrm{Ag}_{\mathrm{x}} \mathrm{TaWO}_{6} \cdot \mathrm{H}_{2} \mathrm{O}$ doped with silver with molar ratios $\mathrm{H} / \mathrm{Ag}$ of the order of $1: 0.25 ; 1: 0.5 ; 1: 2$ and 1:4. Raman measurements were performed on each of the different doping samples before and after thermal treatments at temperatures of 440,550 and $700^{\circ} \mathrm{C}$ during $2 \mathrm{~h}$, $15 \mathrm{~h}$, and $90 \mathrm{~min}$, respectively. This experiment was based on a study literature, by Cazzanelli et al. in which the pure samples of $\mathrm{HTaWO}_{6}$ were submitted to thermal treatments at the same temperatures [15].

\section{Results}

\section{The DSC/TG results}

The result of thermogravimetry for $\mathrm{x}=0.5$ sample is showed in the Figure 2 compared with $\mathrm{HTaWO}_{6} \cdot \mathrm{H}_{2} \mathrm{O}$ sample studied before [14]. Due defects found in others samples, such mass increasing, we do not show the thermogravimetry plots for the others samples.

If we do not take into account spurious effects we can demonstrate that mass loss for $\mathrm{x}=0.5$ sample was about $2 \%$, much lower than $5 \%$ mass loss of the pure sample $\mathrm{HTaWO}_{6} \cdot \mathrm{H}_{2} \mathrm{O}$. The $\mathrm{x}=0.5$ sample was the best loss mass plot between doped samples. The loss mass curve is approximately the same shape as the $\mathrm{HTaWO}_{6} \cdot \mathrm{H}_{2} \mathrm{O}$ curve with all massloss process, but slower than the pure one. For $\mathrm{H}_{0.5} \mathrm{Ag}_{0.5} \mathrm{TaWO}_{6} \cdot \mathrm{H}_{2} \mathrm{O}$ sample we calculated mass percentages for $\mathrm{H}, \mathrm{Ag}, \mathrm{O}$, Ta and $\mathrm{W}$ ions and the results were $0.47,10.11,21.0,33.93$ and $34.48 \%$ respectively. The mass loss for $\mathrm{TaWO}_{55}$ formation occur with loss of $\mathrm{O}^{-2}, \mathrm{H}^{+}$, and $\mathrm{Ag}^{+}$ions. The theoretical total mass loss was about $15 \%$ including the $\mathrm{Ag}^{+}$ion. Therefore, the mass loss of $\mathrm{Ag}^{+}$ions is unlikely. In short, the loss mass reactions do not degrade the HAg1:1 sample $(x=0.5)$ and the final result is $\mathrm{AgTaWO}_{6}$ with vacancies instead $\mathrm{TaWO}_{5.5}$ compound.

The Figure 3 shows results about Differential Scanning Calorimetry (DSC) for all samples studied $(\mathrm{x}=0.8,0.67,0.5$, and 0.25$)$ in the $35-570^{\circ} \mathrm{C}$ range. The DSC plots show anomalies of baseline deviation caused by the difference in heat capacity between the sample and the reference cadmium.

The first phase transition occurs in the samples with $\mathrm{x}=0.5$ and

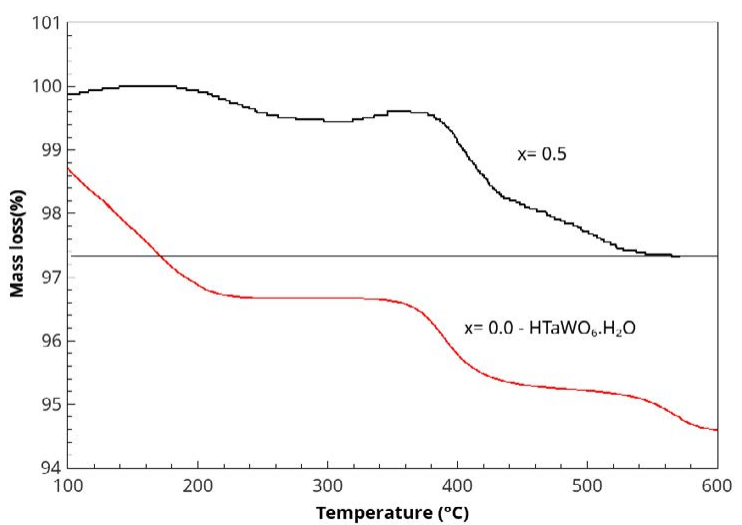

Figure 2: Thermogravimetric plots for both $\mathrm{H}_{0.5} \mathrm{Ag}_{0.5} \mathrm{TaWO}_{6} \mathrm{H}_{2} \mathrm{O}$ and $\mathrm{HTaWO}_{6}$ $\mathrm{H}_{2} \mathrm{O}$ pure samples. The line is a guide for eyes.

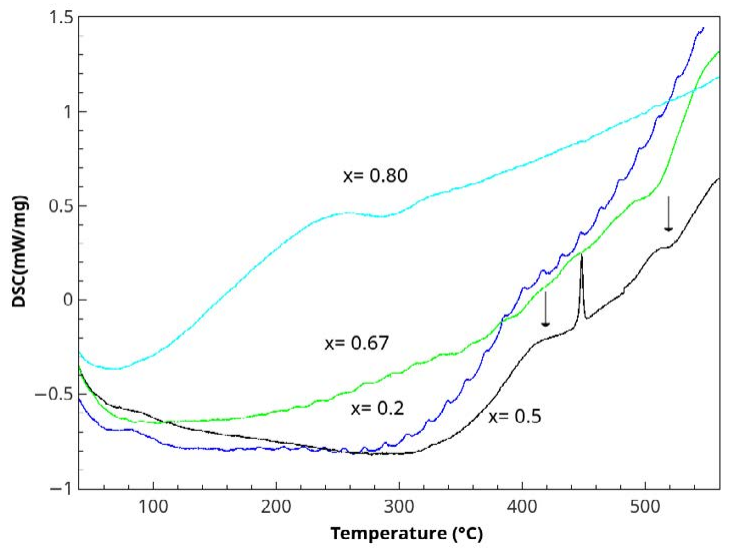

Figure 3: Differential scanning calorimetry (DSC) plots for four pyroclhore samples studied $(x=0.80-0.2)$. The arrows show important phase transitions (see the text).

$\mathrm{x}=0.2 \mathrm{Ag}^{+}$concentration is grain boundary water loss about $80^{\circ} \mathrm{C}$. It is observed in DSC plot by baseline change and finishes at $100^{\circ} \mathrm{C}$. This transition is not observed for samples with $\mathrm{x}=0.80$ and 0.67 $\mathrm{Ag}^{+}$concentration rate. Maybe it is evidence of last samples are less hygroscopic than the first ones.

The next endothermic transformation is around $300^{\circ} \mathrm{C}$. In the $\mathrm{x}=0.5$ sample, it occurs at $320^{\circ} \mathrm{C}$. There is a conformational transition of the pyrochlore structure finishing at $420^{\circ} \mathrm{C}$. The peak between 440 $460^{\circ} \mathrm{C}$ is endothermic transformation, maybe a pyrochlore-trirutile transition. From $460^{\circ} \mathrm{C}$ we observe the trirutile structure crystallization that tends to amorphization after $520^{\circ} \mathrm{C}$.

In the $\mathrm{x}=0.20$ sample, we observe a continuous phase change starting at $295^{\circ} \mathrm{C}$. The transition phase that occurs in $\mathrm{x}=0.50$ does not occur in the $\mathrm{x}=0.20$ sample. The peak between $440-460^{\circ} \mathrm{C}$ does not appear. Besides that, the baseline change is not clear, indicating the sample remains in the pyrochlore structure as is showed in the Raman Spectrum after DSC in the next section.

The sample with $\mathrm{x}=0.80$ shows a baseline change from $100^{\circ} \mathrm{C}$ to $460^{\circ} \mathrm{C}$. This change corresponds to conformational transformation, maybe the pyrochlore-trirutile change. However, there is no abrupt change in the thermogravimetry change after $460^{\circ} \mathrm{C}$, we can conclude the sample do not change its structure for trirutile phase at least completely like we can observe in the next section.

\section{Vibrational spectroscopies}

Group theory analysis: The number of vibrational modes in the center of the first Brillouin zone $(\Gamma=0)$ in terms of irreducible representations of point groups was determined by the group factor method analysis proposed by Rousseau et al. [16] for each structure. The results are shown in Table 2, where the first two columns correspond to the species of atoms and their respective occupations sites (in Wyckoff notation) in the unit cell as well as their respective symmetries. The third column shows the distribution of degrees of freedom in terms of irreducible representations of group's factors. For each space group, are provided separately the distributions of vibrational modes that are active in infrared $\left(\Gamma_{\mathrm{IR}}\right)$ and Raman $\left(\Gamma_{\mathrm{R}}\right)$ spectroscopies as well as acoustic $\left(\Gamma_{\mathrm{AC}}\right)$ and silent $\left(\Gamma_{\mathrm{S}}\right)$ modes. For the space group $\mathrm{Fd} 3 \mathrm{~m}(\mathrm{Z}=8)$ of pyrochlore $\mathrm{AB}^{\prime} \mathrm{B}^{\prime \prime} \mathrm{O}_{6}$, the distribution of 54 degrees of freedom in terms of irreducible representations of the group factor $\mathrm{O}_{h}$ is given by $\mathrm{A}_{1 \mathrm{~g}}+2 \mathrm{~A}_{2 \mathrm{u}}+\mathrm{E}_{\mathrm{g}}+2 \mathrm{E}_{\mathrm{u}}+2 \mathrm{~F}_{1 \mathrm{~g}}+6 \mathrm{~F}_{1 \mathrm{u}}+4 \mathrm{~F}_{2 \mathrm{~g}}+3 \mathrm{~F}_{2 \mathrm{u}}$ (Table 2). In this total, the 


\begin{tabular}{|c|c|c|}
\hline Ions & Wickoff sites/Symmetry & Modes distribution \\
\hline$A$ & $8 \mathrm{~b} / \mathrm{T}_{\mathrm{d}}$ & $\mathrm{F}_{1 \mathrm{u}}+\mathrm{F}_{2 \mathrm{~g}}$ \\
\hline $\mathrm{B}^{\prime} / \mathrm{B}^{\prime \prime}$ & $16 c / D_{3 d}$ & $\mathrm{~A}_{2 \mathrm{u}}+\mathrm{E}_{\mathrm{u}}+2 \mathrm{~F}_{1 \mathrm{u}}+\mathrm{F}_{2 \mathrm{u}}$ \\
\hline 0 & $48 f / C_{2 v}^{d}$ & $\mathrm{~A}_{1 \mathrm{~g}}+\mathrm{A}_{2 \mathrm{u}}+\mathrm{E}_{\mathrm{g}}+\mathrm{E}_{\mathrm{u}}+2 \mathrm{~F}_{1 \mathrm{u}}+3 \mathrm{~F}_{2 \mathrm{~g}}+2 \mathrm{~F}_{2 \mathrm{u}}$ \\
\hline \multicolumn{3}{|c|}{$\Gamma_{T}=A_{1 g}+2 A_{2 u}+E_{g}+2 E_{u}+2 F_{1 g}+6 F_{1 u}+4 F_{2 g}+3 F_{2 u}$} \\
\hline$\Gamma_{R}=A_{1 g}+E_{g}+4 F_{2 g}$ & & $\Gamma_{\mathbb{R}}=5 \mathrm{~F}_{1 \mathrm{u}}$ \\
\hline$\Gamma_{s}=2 A_{2 u}+2 E_{u}+2 F_{1 g}+3 F_{2 u}$ & & $\Gamma_{\mathrm{ac}}=\mathrm{F}_{1 \mathrm{u}}$ \\
\hline
\end{tabular}

Table 2: Group Theory analysis to the $\mathrm{KTaWO}_{6}$ group factor $\mathrm{O}_{\mathrm{h}}$

modes $\mathrm{A}_{1 \mathrm{~g}}+\mathrm{E}_{\mathrm{g}}+4 \mathrm{~F}_{2 \mathrm{~g}}$ are Raman active while the 6 modes that transform as the translations of the network $\left(\mathrm{F}_{1 \mathrm{u}}\right)$, five are active in infrared spectroscopy $\left(5 \mathrm{~F}_{1 \mathrm{u}}\right)$ and corresponds to a triply degenerate acoustic modes. Moreover, other modes $2 \mathrm{~A}_{2 \mathrm{u}}+2 \mathrm{E}_{\mathrm{u}}+2 \mathrm{~F}_{1 \mathrm{~g}}+3 \mathrm{~F}_{2 \mathrm{u}}$, are inactive in the vibrational spectroscopy, and referred to as silent modes.

$\mathrm{KTaWO}_{6}$ vibrational spectrum: There are several results in the Raman spectroscopy literature in pyrochlore type compounds as a basis for the discussion of our results of Raman spectroscopy of dopedsamples $\mathrm{Ag}_{\mathrm{x}} \mathrm{H}_{1-\mathrm{x}} \mathrm{TaWO}_{6} \cdot \mathrm{xH}_{2} \mathrm{O}$. Firstly we show the vibrational spectra of the precursor sample $\mathrm{KTaWO}_{6}[14]$ pyrochlore as reference. In general, the octahedral internal modes of both the $\mathrm{KTaWO}_{6}$ as to its protonic derivatives $(\mathrm{H}$ or $\mathrm{D})$ show the same bands distribution [17]. Figure $4 \mathrm{a}$ shows the Raman spectrum of $\mathrm{KTaWO}_{6}$ measured at room temperature with radiation $\lambda=514.5 \mathrm{~nm}$ and typical power of $50 \mathrm{~mW}$.

There is a subtle difference in the wave number region of 130-300 $\mathrm{cm}^{-1}$ of Raman spectra of the hydrated and non-hydrated samples and in the water vibration modes region too (above $1500 \mathrm{~cm}^{-1}$ ). Comparing the Raman spectrum of $\mathrm{KTaWO}_{6}$ obtained by us and those of ref. [17] we can see that our sample is in the hydrated form. Furthermore, there is a centered bands outspread around 140 and $690 \mathrm{~cm}^{-1}$ in the nonhydrated sample into two bands with wave number 142, 195 (137 and $193 \mathrm{~cm}^{-1}$ in ref. [16]) and $650,715 \mathrm{~cm}^{-1}$, respectively. Figure $4 \mathrm{~b}$ shows the Raman spectrum of said sample in the water spectral region and therefore the presence of water in the sample is confirmed. The first region, 1600 to $2000 \mathrm{~cm}^{-1}$, corresponds to the angle $(\mathrm{H}-\mathrm{O}-\mathrm{H} \delta(\mathrm{OH})$ ) deflection, while the second, 2700 to $3600 \mathrm{~cm}^{-1}$, corresponds to the bond $(\mathrm{O}-\mathrm{H} \delta(\mathrm{OH}))$ stretching.

The transmittance spectrum in $\mathrm{KTaWO}_{6}$ infrared, measured at ambient temperature in the region between 250 and $1275 \mathrm{~cm}^{-1}$, is shown in Figure 5, where we can observe five centered bands at 270, $340,390,610$ and $720 \mathrm{~cm}^{-1}$. Note that above $800 \mathrm{~cm}^{-1}$ there are no indication of modes that are both Raman and infrared active and the weak mode in $340 \mathrm{~cm}^{-1}$ and an intense one in $719 \mathrm{~cm}^{-1}$; both appear in infrared and Raman spectra.

We can analyze the $\mathrm{KTaWO}_{6}$ Raman spectrum in terms of the free vibrations of octahedra $(\mathrm{Ta} / \mathrm{W}) \mathrm{O}_{6}$ and if there is, the modes of coupling between them. As we already know the mode $v_{1}\left[(\mathrm{Ta} / \mathrm{W}) \mathrm{O}_{6}\right]$ is localized around $850 \mathrm{~cm}^{-1}$, therefore in $\mathrm{KTaWO}_{6}$ this mode is located at 894 $\mathrm{cm}^{-1}$. The band at $956 \mathrm{~cm}^{-1}$ is not a $v_{1}$ outspread mode due to its large energy difference $\left(62 \mathrm{~cm}^{-1}\right)$. This band is a strong indication of coupled octahedral movement, as observed for $\mathrm{LiTaWO}_{6}$. The bands at 340 and $720 \mathrm{~cm}^{-1}$, observed in the $\mathrm{KTaWO}_{6}$ Raman spectrum and not observed in ref. [17] may be leakage in the modes $v_{4}$ e $v_{3}$ of the infrared spectrum for the Raman spectrum.

This is possible due to positional disorder observed for the cations Ta and W. Thus, the bands $60,142,244,653,894$ and $956 \mathrm{~cm}^{-1}$ are the Raman fundamental modes of hydrated $\mathrm{KTaWO}_{6}$, whereas the bands 340 and $719 \mathrm{~cm}^{-1}$ are infrared fundamental modes and other modes in 195, 425 and $450 \mathrm{~cm}^{-1}$ are the network modes associated to water molecule.

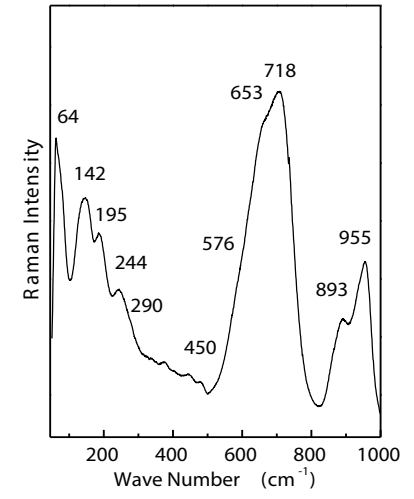

(a)

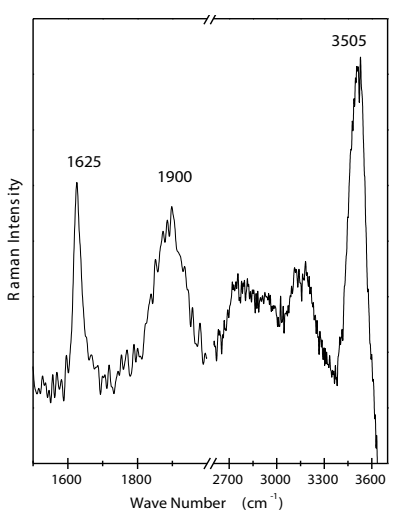

(b)
Figure 4: $\mathrm{KTaWO}_{6}$ Raman spectrum at room temperature with $\lambda=514.5$ $\mathrm{nm}$ radiation and $50 \mathrm{~mW}$ power at (a) low wavenumber. (b) spectral water wavenumber region.

Raman Spectra of $\mathrm{H}_{1-\mathrm{x}} \mathrm{Ag}_{\mathrm{x}} \mathrm{TaWO}_{6} \cdot \mathrm{H}_{2} \mathrm{O}$ compound: Figure 6a shows the Raman spectra of the compounds at room temperature with $\mathrm{H}_{1-\mathrm{x}} \mathrm{Ag}_{\mathrm{x}} \mathrm{TaWO}_{6}$ with $\mathrm{x}=0.00,0.20,0.33,0.50,0.67,0.80$ and 1.00 , where the slanted lines are guides for the eyes. The effect of doping is best seen through the bands around 150, 700 and $900 \mathrm{~cm}^{-1}$. In general the wave numbers of the modes decreases with the increase of concentration rate of $\mathrm{Ag}+$, and a light scattering is observed around concentration 0.67 and $x=0.33$ for silver $v_{1}(2)$, as shown by Figure $6 \mathrm{~b}$. This is due to the fact that the hydrogen bonds lose their influence on the energy of such bands, so that there is a weakening of the connections Ta/W-O. According to Santis [14] diffraction peaks remain unchanged for different concentrations $\mathrm{x}$, with all reflections belonging to cubic space group $\mathrm{Fd} 3 \mathrm{~m}\left(\mathrm{O}_{\mathrm{h}}{ }^{7}\right)$. Raman spectroscopy was also able to complement these results, where the band patterns observed are consistent with that of a pyrochlore compound.

In order to study the thermal stability of the compound $\mathrm{H}_{1}$. ${ }_{x} \mathrm{Ag}_{\mathrm{x}} \mathrm{TaWO}_{6} \cdot \mathrm{H}_{2} \mathrm{O}$, the Raman spectra of the compounds were measured in function of the temperature. Three Raman studies were conducted with temperature on samples $\mathrm{HTaWO}_{6}$ : (i) samples after heat treatment at high temperatures, (ii) another in samples after Thermogravimetry (TG) experiments and Differential Scanning Calorimetry (DSC) and (iii) in high temperatures within the temperature ranges at which the DSC detects the phase shift. Cazzanelli et al. [15] was one of the pioneers in the study of the Raman spectrum in pure samples of $\mathrm{HTaWO}_{6}$, whose work also includes photo-induced transformations. This last experiment we cannot perform due to limitations of the experimental apparatus used, which uses the geometry type "backscattering" $\left(180^{\circ}\right)$, whose optical path is too large, causing the light to reach the sample with reduced power for the experiment conduction. So, we limit ourselves to doing the Raman experiments with heat treatment. The results of these Raman studies for compounds $\mathrm{H}_{1-\mathrm{x}} \mathrm{Ag}_{\mathrm{x}} \mathrm{TaWO}_{6} \cdot \mathrm{H}_{2} \mathrm{O}$ with $\mathrm{x}=0.80$ after heat treatments at temperatures of $25,440,550$ and $700^{\circ} \mathrm{C}$ are shown 


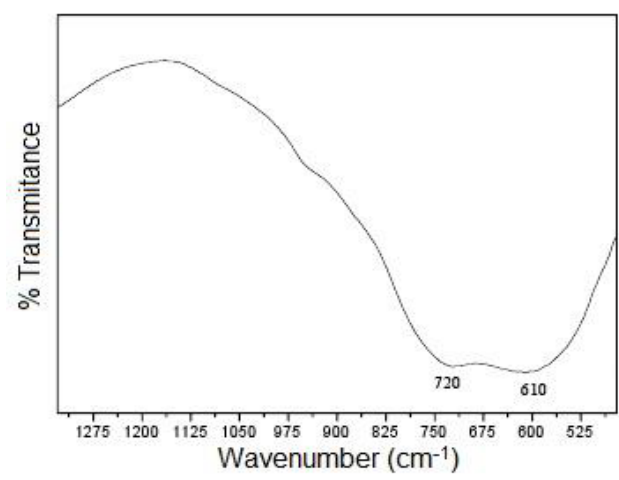

(a)

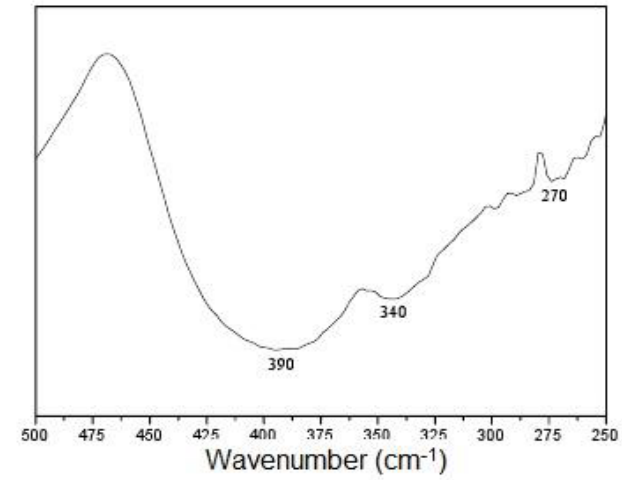

(b)

Figure 5: Infrared transmitance spectra of KTaWO6 compound. (a) 525-1275 $\mathrm{cm}^{-1}$ wavenumber region. (b) 250 a $500 \mathrm{~cm}^{-1}$ wavenumber region.

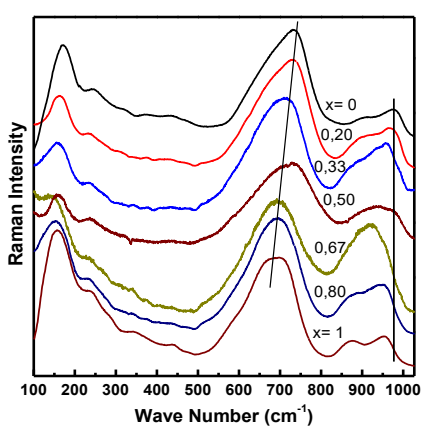

(a)

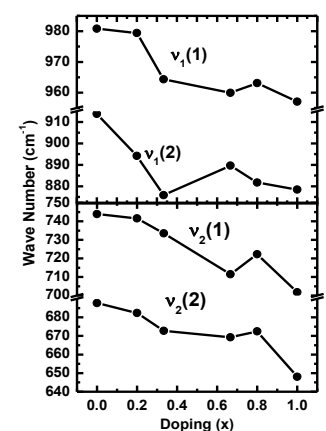

(b)
Figure 6: Raman spectra at room temperature of $\mathrm{H} 1-\mathrm{xAgxTaWO6}$ system with $x=0.00,0.20,0.33,0.50,0.67,0.80$ e 1.00 (a) spectra, (b) wavenumber doping $x$ dependence.

in Figure 7. Spectra were obtained at room temperature, which shows that the transformation is irreversible. The transition observed around temperature $700^{\circ} \mathrm{C}$ is typical of the dehydration process of hydrated compounds [18]. Because of the limitation of the experimental technique, the two bands below $100 \mathrm{~cm}^{-1}$ could not be observed in the spectrum referent to the temperature $700^{\circ} \mathrm{C}$, but the bands above this collapse into a single broad band around $300 \mathrm{~cm}^{-1}$. Moreover, the high wave numbers bands undergo a shift towards lower wave numbers due to the oxygen deficiency of octahedra $\mathrm{Ta} / \mathrm{WO}_{6}$.

Figure 8 shows the Raman spectra of the samples $\mathrm{H}_{1-\mathrm{x}} \mathrm{Ag}_{\mathrm{x}} \mathrm{TaWO}_{6}$. $\mathrm{H}_{2} \mathrm{O}$ with $\mathrm{x}=0.20,0.33,0.67$ and 0.80 at room temperature after being submitted to heat treatment at $700^{\circ} \mathrm{C}$. Note that for all the concentrations, the Raman spectra of these compounds are similar to that of compound $\mathrm{TaWO}_{5,5}$ (see Figure 4 of ref. [18]), which means that in this heat treatment the sample is completely dehydrated.

Dependent temperature RAMAN studies: These studies were conducted to better observe the changes occurring during the heating experiment done in DSC/TG. Figure 9 shows the measured spectra of the compounds at room temperature $\mathrm{H}_{1-\mathrm{x}} \mathrm{Ag}_{\mathrm{x}} \mathrm{TaWO}_{6} \cdot \mathrm{H}_{2} \mathrm{O}$, with $\mathrm{x}=0.20$, 0.50 and 0.67 after being subjected to thermo-gravimetry experiments. Note through this figure that the samples with $\mathrm{x}=0.20$ and 0.67 pyrochlore structure was maintained while for $\mathrm{x}=0.50$ it underwent dehydration transforming into compound $\mathrm{TaWO}_{5.5}$.

Figures 10 and 11 shows the temperature-dependent Raman

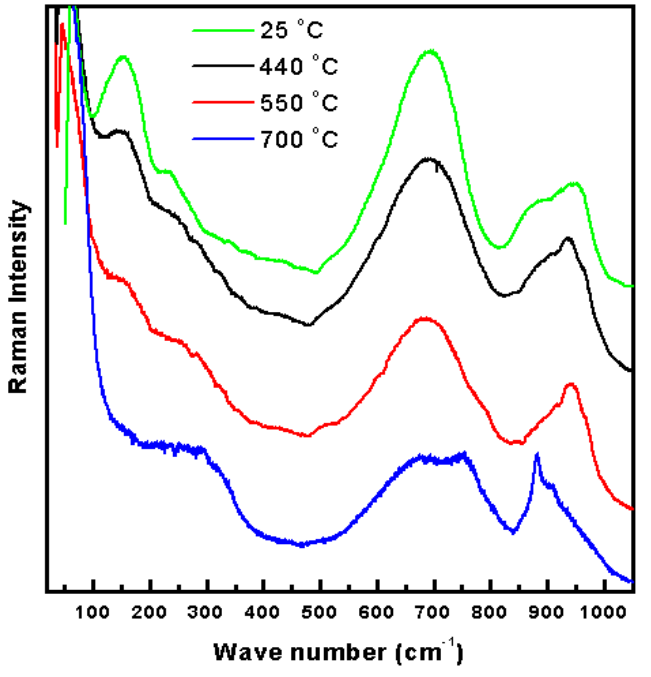

Figure 7: $\mathrm{H}_{1-x} \mathrm{Ag}_{\mathrm{x}} \mathrm{TaWO}_{6} \cdot \mathrm{H}_{2} \mathrm{O}$ Raman spectra compound with $\mathrm{x}=0.80$ after 25, 440,550 and $700^{\circ} \mathrm{C}$ heat treatment.

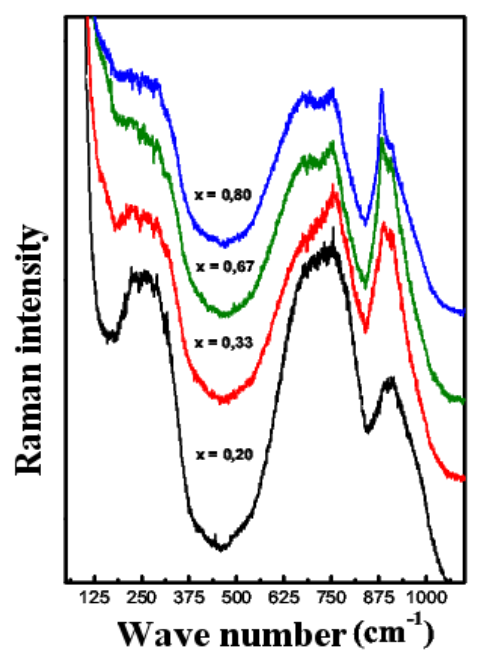

Figure 8: $\mathrm{H}_{1-x} \mathrm{Ag}_{\mathrm{x}} \mathrm{TaWO}_{6}$ Raman spectra compound with $\mathrm{x}=0.20,0.33,0.67 \mathrm{e}$ 0.80 , at room temperature after $700^{\circ}$ heat treatment. 


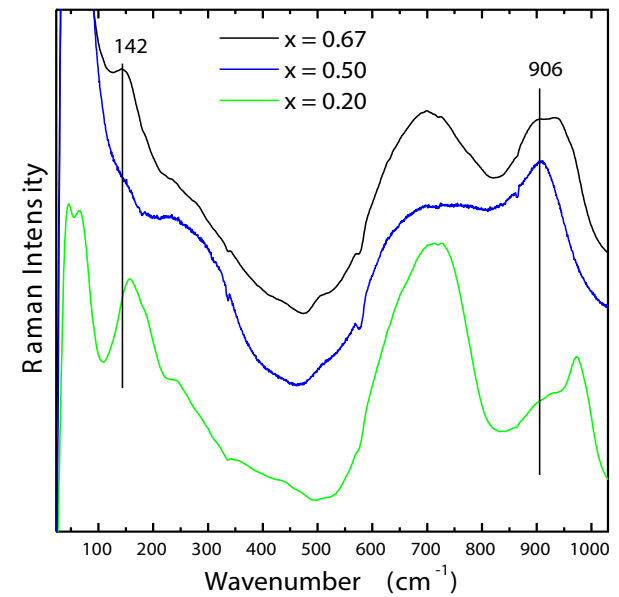

Figure 9: $\mathrm{H}_{1-x} \mathrm{Ag}_{\mathrm{x}} \mathrm{TaWO}_{6} \cdot \mathrm{H}_{2} \mathrm{O}$ Raman spectra compound, with $\mathrm{x}=0.20,0.50 \mathrm{e}$ 0.67 after DSC experiment.

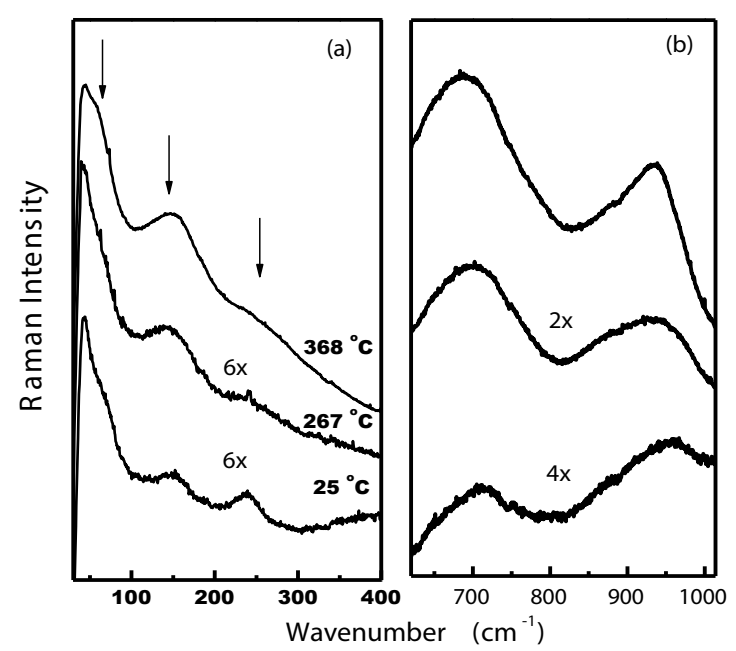

Figure 10: $\mathrm{H}_{0.2} \mathrm{Ag}_{0.8} \mathrm{TaWO}_{6} \cdot \mathrm{H}_{2} \mathrm{O}$ Raman spectra compound at 25,267 e $368^{\circ} \mathrm{C}$ temperatures.

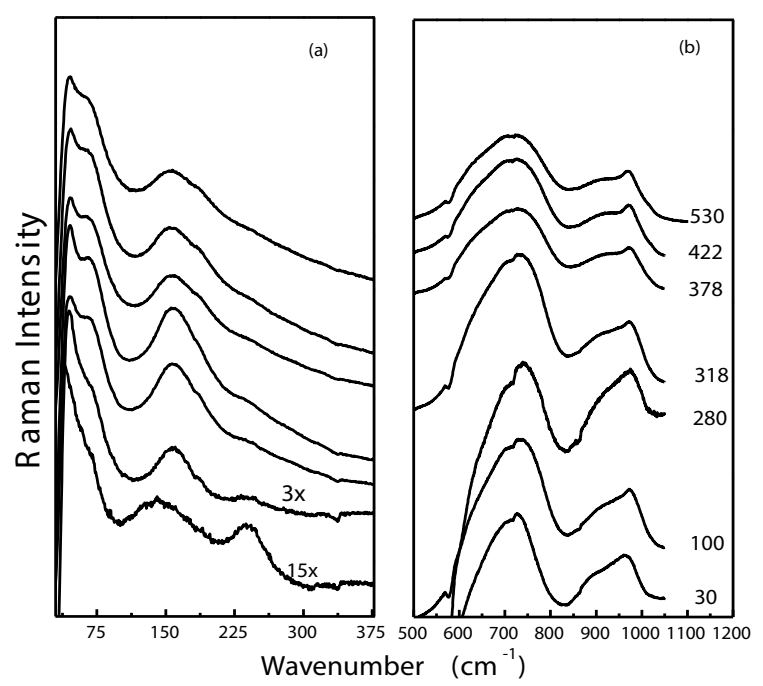

Figure 11: $\mathrm{H}_{0.5} \mathrm{Ag}_{0.5} \mathrm{TaWO}_{6} \cdot \mathrm{H}_{2} \mathrm{O}$ Raman spectra at $30-530^{\circ} \mathrm{C}$ temperatures for both (a) low and (b) high wavenumber regions. spectra for the compounds $\mathrm{H}_{0.2} \mathrm{Ag}_{0.8} \mathrm{TaWO}_{6} \cdot \mathrm{H}_{2} \mathrm{O}$ and $\mathrm{H}_{0.5} \mathrm{Ag}_{0.5} \mathrm{TaWO}_{6}$. $\mathrm{H}_{2} \mathrm{O}$ respectively. Note that no significant changes were observed in these spectra, only the disappearance of the band of $240 \mathrm{~cm}^{-1}$ and a small displacement of the band between 900 and $1000 \mathrm{~cm}^{-1}$ for low wave numbers, reflecting the lattice expanding effect with increasing temperature. For both samples the Raman spectra suggest that the pyrochlore structure is maintained in the observed temperature ranges. The doublet observed above $900 \mathrm{~cm}^{-1}$ for compound with $\mathrm{x}=0.50$ concentration becomes only one band for $\mathrm{x}=0.80$. As these bands are associated to the almost-free octahedra movements and sharing the vertices, the temperature increase means that there is one degeneracy among these parts, if not observed for $\mathrm{x}=0.50$.

\section{Conclusion}

Samples type $\mathrm{H}_{1-\mathrm{x}} \mathrm{Ag}_{\mathrm{x}} \mathrm{TaWO}_{6} \cdot \mathrm{H}_{2} \mathrm{O}$ show the characteristic spectrum of pyrochlore samples, with some interesting features. Among them, we can mention:

- Wavenumber dependence on the Ta-O and W-O modes in relation to the increase of doping. The modes reduce the wavenumber with the increase of doping;

- Possible leakage in modes $v_{4}$ and $v_{3}$ of the infrared (340 and $720 \mathrm{~cm}^{-1}$ bands);

- It was not confirmed pyrochlore-trirutile transformation for $\mathrm{H}_{1-\mathrm{x}} \mathrm{Ag}_{\mathrm{x}} \mathrm{TaWO}_{6} \cdot \mathrm{H}_{2} \mathrm{O}$ nor with Raman studies with heat treatment at $700^{\circ} \mathrm{C}$ for $90 \mathrm{~min}$, or with results of DSC/TG thermal analysis and Raman spectroscopy with high temperatures. At least for the doped samples with silver it was not detected this transition [19];

- The transformation that may have occurred in the pyrochlore compounds is the hydrogen mass loss. Our study in the sample with the concentration rate $\mathrm{x}=0.50$ showed a loss of approximately $2 \%$ [19]. Lower than that recorded for pure sample $\mathrm{HTaWO}_{6} \cdot \mathrm{H}_{2} \mathrm{O}$ and far below if the $\mathrm{H}_{1-\mathrm{x}} \mathrm{Ag}_{\mathrm{x}} \mathrm{TaWO}_{6} \cdot \mathrm{H}_{2} \mathrm{O}$ sample also lost $\mathrm{Ag}^{+}$mass (15\%).

\section{Acknowledgments}

D. Valim acknowledge E.N. Silva for his conversations about Group Theory and vibrational modes. D. Valim, AG Souza Filho, JM Filho, OL Alves, M.A.C de Santis, and E.N. Silva acknowledge the Brazilian agencies, CNPq, CAPES, FUNCAP, and FAPESP for financial support.

\section{References}

1. Chelgani SC, Hart B, Biesinger M, Marois J, Ourriban M (2014) Pyrochlore surface oxidation in relation to matrix Fe composition: A study by X-ray photoelectron spectroscopy. Minerals Engineering 55: 165-171.

2. Hidalgo J, Colet-Lagrille M, Mukasyan A, Fuenzalida VM, Vargas T (2015) Synthesis of nanostructured zirconia by anodization at low potentials. Cryst Res Technol 50: 879-883.

3. Catti M, Mari CM, Valerio G (1992) Potential energy maps and $\mathrm{H}+$ conduction mechanism in HTaWO6 $\times x_{2} 2$ pyrochlore. J Solid State Chem 98: 269-277.

4. Groult D, Raveau B, Michel C Weekly Records of the Sessions of the Academy of Sciences SeriesC 274: 374.

5. Subramanian MA, Aravamudan G, Rao GVS (1983) Oxide pyrochlores- a review. Prog Solid State Chem 15: 55-143.

6. Subramanian MA, Toby $B H$, Ramirez AP, Marshall WZ, Sleight AW, et al (1996) Colossal Magnetoresistance Without Mn3+/Mn4+ Double Exchange in the Stoichiometric Pyrochlore TI2Mn2O7. Sci 273: 81-84.

7. Kennedy BJ, Vogt T (1996) Structural and Bonding Trends in Ruthenium Pyrochlores. J Solid State Chem 126: 261-270.

8. Yonezawa S, Muraoka Y, Matsushita Y, Hiroi Z (2004) Superconductivity in a pyrochlore-related oxide $\mathrm{KOs}_{2} \mathrm{O}_{6}$. J Phys Condens Matter 16: L9-L12. 
Citation: Valim D, Filho AGS, Filho JM, Alves OL, de Santis MAC, et al. (2018) Vibrational and Thermal Properties of lonic Conductors Type Pirochlore $\mathrm{H}_{1-\mathrm{x}} \mathrm{Ag}_{\mathrm{x}} \mathrm{TaWO}_{6} \cdot \mathrm{nH}_{2} \mathrm{O}$. J Material Sci Eng 7: 483. doi: 10.4172/2169-0022.1000483

Page 7 of 7

9. Mari CM, Bonino F, Catti M, Pasinetti R, Pizzini S (1986) Sol Stat lon 18: 1013.

10. Mari CM, Catti M, Castelli M (1986) A Characterization of $\mathrm{KTaWO}_{6} \cdot \mathrm{H}_{2} \mathrm{O}$. Mat Res Bull 21: 773-778.

11. Zarbin AJG, Alves OL, Amarilla JM, Rojas RM, Rojo JM (1999) Chem Matter 11: $1652-1658$

12. Galembeck A, Alves OL (1999) Thermal behavior of $\alpha-B a\left(F_{e S}\right)_{2}$ and $\mathrm{AgFeS}_{2}$ : quasi-unidimensional and $3 \mathrm{D}$ network compounds prepared from ion-exchange on the same precursor J Mater Sci 34: 3275-3280.

13. Díaz-Guillén JA, Fuentes AF, Díaz-Guillén MR, Almanza JM, Santamaría J, et al. (2009) The effect of homovalent A-site substitutions on the ionic conductivity of pyrochlore-type $\mathrm{Gd}_{2} \mathrm{Zr}_{2} \mathrm{O}_{7}$. J Power Sour 186: 349.

14. De Santis MAC (2006) Lamellar structure versus pyrochloric structure: obtaining compounds of the type 'IND IND. 1-x"Ag IND. x"Ta'W'O IND. 6 'and linear amine insertion / insertion reaction.

15. Cazzanelli E, Mariotto G (1992) Sol Stat Ion 53-56: 38

16. Rousseau DL, Bauman RP, Porto SPS (1981) Normal mode determination in crystals. J Raman Spectro 10: 253.

17. Cazzanelli E, Mariotto G (1991) Sol Stat Ion 46: 135.

18. Catti M, Cazzanelli E, Mari CM, Mariotto G (1993) Trirutile phases of HTaWO[sub 6][center dot]xH[sub 2]O: Vibrational properties and electrical conductivity. J Solid State Chem 107: 108

19. Valim $D$ (2009) Espectroscopia vibracional e de impedância de A1-XA'xTaWO6. $\mathrm{nH} 2 \mathrm{O}\left(\mathrm{A}=\mathrm{H}, \mathrm{Li}, \mathrm{A}^{\prime}=\mathrm{Ag}, \mathrm{H}\right), \mathrm{PhD}$ thesis, UFC-Universidade Federal do Ceará, Fortaleza, Brazil. 